\title{
NONLINEAR STABILITY ANALYSIS OF A RADIALLY RETRACTABLE SUSPEN-DOME
}

\author{
Jianguo Cai*, Yangqing Liu, Jian Feng and Yongming Tu \\ Key Laboratory of C \& PC Structures of Ministry of Education, National Prestress Engineering Research Center, \\ Southeast University, Nanjing 210096, China \\ *(Corresponding author: E-mail: caijg_ren@hotmail.com; j.cai@seu.edu.cn)
}

Received: 23 December 2015; Revised: 3 March 2016; Accepted: 26 May 2016

\begin{abstract}
A radially retractable roof structure based on the concept of the suspen-dome is proposed in this paper. The radially foldable bar structure are strengthened by the lower cable-strut system. Then the buckling capacity of a radially retractable suspen-dome was investigated. The geometrically non-linear elastic buckling and elasto-plastic buckling analyses of the hybrid structure were carried out. Then the effects of different structural parameters, such as the rise-span ratio, beam section, area and pre-stress of lower cable-strut systems, on the failure load were investigated. The influence of imperfections on the elasto-plastic buckling loads was also discussed. The results show that the critical buckling load is reduced by taking account of material non-linearity. Furthermore, increasing the rise-to-span ratio or the cross-section area of steel beams notably improves the stability performance of the structure. However, the area and pre-stress of cable-strut systems pose small effect on the structural stability. It can also be found that the suspen-dome is highly imperfection sensitive and the reduction of the failure load due to imperfections is considerable.
\end{abstract}

Keywords: Retractable roof, suspen-dome, stability, elasto-plastic, failure load

DOI: 10.18057/IJASC.2017.13.2.2

\section{INTRODUCTION}

Retractable roof structures, which enable the users of recreational facilities to enjoy open air as long as allowed by the weather, are playing an important role in the development of multi-functional sports and culture facilities. With one or more degrees of freedom, deployable/foldable structures can expand to form a large opening space, which make them ideal for use as retractable roofs [1]. However, for a retractable roof, which is unlike a demountable, mobile, transportable or temporary structure, there is a permanent structure in a fixed location [2]. Within the boundaries given by this permanent structure, the retractable roof is capable of undergoing a geometric transformation between two distinct configurations, usually referred to as the open and closed configurations. In the past two decades, many concepts of deployable structures have been proposed for retractable roof structures [3]. Among these concepts, there is a new type of retractable structures which use angulated scissor-like elements, which is proposed by Hoberman [4-6], as basic structural elements. The unit, which consists of a pair of identical angulated rods connected by a revolute joint, subtends a constant angle as their rods rotate while maintain the end pivots on parallel lines [7]. Therefore, it can create a closed-loop mechanism, which is called Hoberman's Linkage. Then this concept was extended by You and Pellegrino [8] who gave birth to a more general family of such structures called the foldable bar structures. On the other hand, they stated that the Hoberman's linkage can be extended by the addition of a pair of bars, connected to one another and to the base linkage by scissor hinges. The resulting structure will be deployable, like the original Hoberman's linkage, provided that the members added to it are not collinear. Repeating the same argument it can be shown that any number of pairs of bars connected by hinges to the base structure will leave its mobility unchanged. That is to say, a foldable structure, as shown in Figure 1, can be made from multi-angulated rods similar to the angulated scissor-like elements introduced in Hoberman's linkage. 

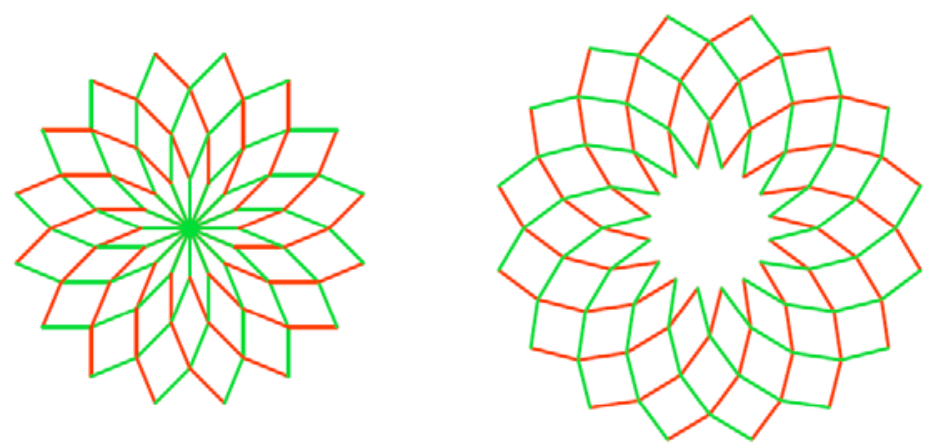

Figure 1. Foldable Bar Structures

However, if this foldable bar structures is used as a retractable roof structure, Teall [9] found that the deformation of the structure, even for a three layer foldable bar structure with a span of $2 \mathrm{~m}$, was quite large under self-weight. This leads to the problem of too small stiffness of the structure to resist the external loads. Mao and Luo [1] and Cai et al. [10] also pointed out that the foldable bar structures are not suitable for the retractable roof structure. They also give some comments and suggestions on how to increase the structural stiffness. However, the stability of the single-layer lattice dome is relatively low when the required span is long [11]. To solve this program, many attempts have been made at increasing flexural stiffness by the use of multiple steel-truss layers. The double-layer dome is advantageous since it has relatively high stability. There is still room for improvement; however, because large weights of the dome cause considerable tension in the outer ring girders. To achieve high stability of single-layer dome and at the same time reduce the burden on boundary structures, the suspen-dome system was developed by Kawaguchi et al [12, 13]. The suspen-dome system has been widely used. Moreover, static and dynamic analysis and tests of the suspen-dome have been carried out by many researchers [14-22].

To advance the practical application of the foldable bar structure in long-span retractable roofs, the concept of suspen-dome is introduced into the foldable bar system. Then a retractable suspen-dome is obtained. This paper shows how to perform a geometrical and material nonlinear finite element analysis by using ANASYS to investigate the stability of the suspen-dome in the closed position. Additionally, the effect of factors such as the geometrical and structural parameters and the asymmetrical distribution of loads will also be taken into consideration in this paper. The imperfection sensitivity including the pattern and scale will be investigated.

\section{STRUCTURAL SYSTEM}

This paper replaces the upper single-layer lattice shell of the suspen-dome by the radially foldable bar system, forming the radially retractable roof structure as shown in Figure 2. It can be found that the suspen-dome has two parts, one is the upper radially foldable bar system and the other is the lower cable-strut system. During the deployment process, the structure unfolds gradually with the radial movement of the boundary joints of the upper foldable bar structures, which is shown in Figure 3. Meanwhile radial cables of the lower cable-strut structure are slack while the length of hoop cables increases continually. Then during the close of the system, hoop cables can be regarded as active cables and radial cables as passive cables. When the structure is totally closed, the lower cable-strut system will have prestresses if we keep tensioning active cables, which is similar to the prestress construction of the general suspen-dome. It can be found that during both the open and close process, the lower cable-strut system is in slackness and only the upper single-layer lattice shell resists external loads. Only the totally closing of the structure will leads to the upper single-layer lattice shell work together with the lower cable-strut system to form a suspen-dome structure. 

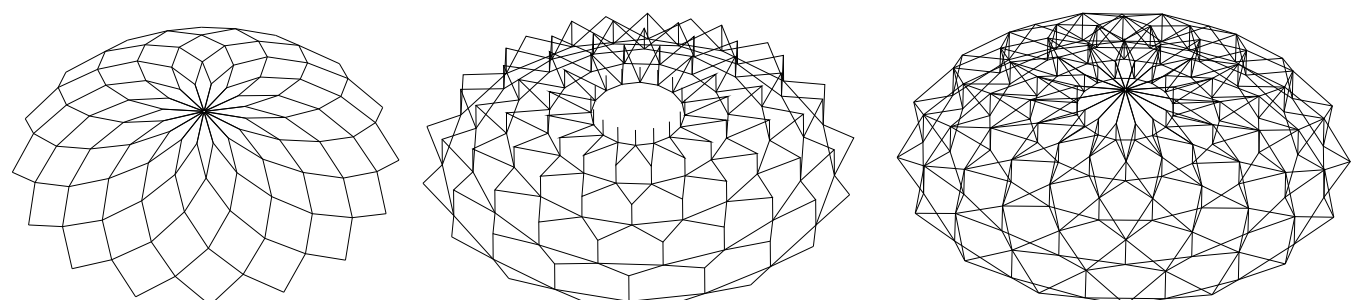

Radially foldable bar system + cable-strut system $=$

$=\quad$ Radially retractable suspen-dome

Figure 2. Concept of the Retractable Suspen-dome

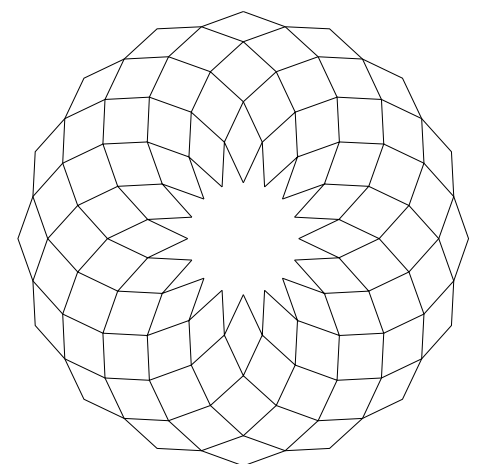

(a) Radially foldable bar system

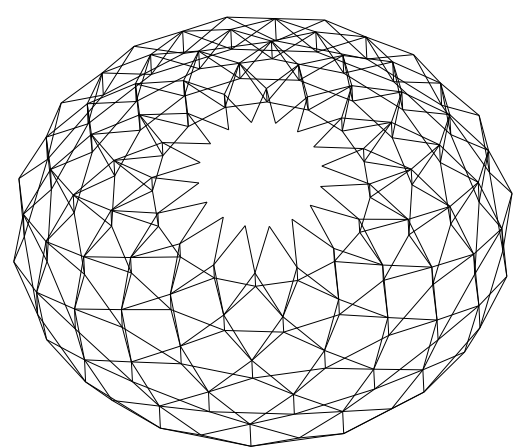

(b) Radially retractable suspen-dome

Figure 3. Radially Retractable System during the Motion

\section{STABILITY BEHAVIOR OF THE RADIALLY RETRACTABLE SUSPEN-DOME}

\subsection{Finite Element Model}

An example of the retractable suspen-dome shown in Figure 4 will be studied in this paper. In this model, every multi-angulated beam has six segments. And the inclined angle between adjacent segments of the beam is $157.5^{\circ}$. The span of the grid shell is $38 \mathrm{~m}$ with the rise-to-span ratio of 0.2 . Other geometric parameters are given in Figure 5.

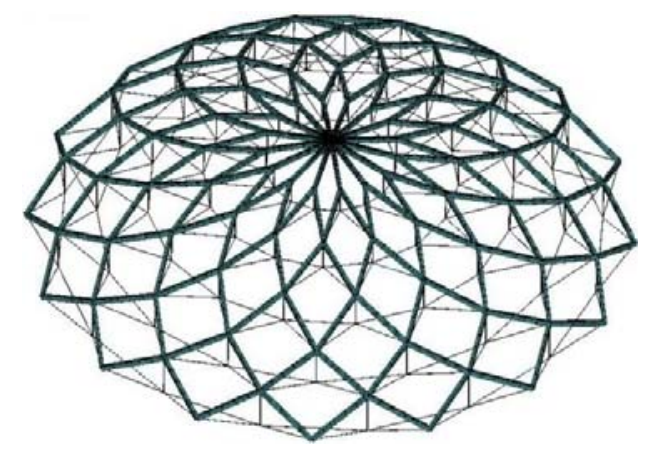

Figure 4. 3D Retractable Suspen-dome in the Closed Configuration 

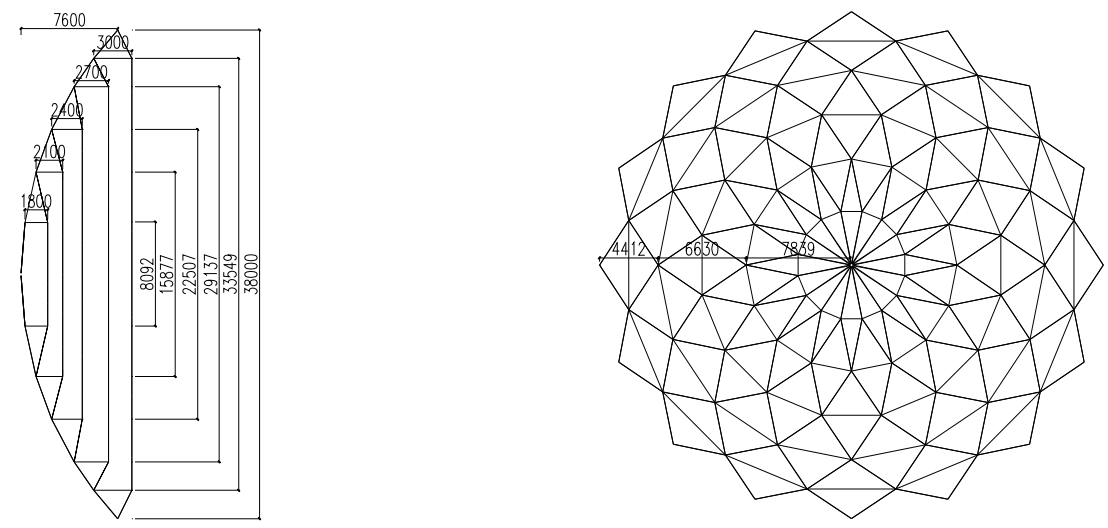

Figure 5. Geometric Parameters of the Retractable Suspen-dome (mm)

The symmetrical load case $g^{+} s$ (dead load +snow load) and asymmetrical load case $g+s / 2$ $(s / 2-$ snow load distributed over half of the span) will be taken into account in all the following computations. The dead load $g$ consists of a self-weight of $0.5 \mathrm{kN} / \mathrm{m}^{2}$ including all the beams and cables. The snow load is applied to the top surface of the structure in the vertical direction with a magnitude of $0.5 \mathrm{kN} / \mathrm{m}^{2}$.

In this paper, the finite element software ANSYS is used to analyze the structure and the geometric nonlinearity is fully considered. The angulated beams are simulated by BEAM188. Joints of these multi-angulated rods are pinned with the release of rotational degree of freedom and the boundary of the retractable suspen-dome is fixed circularly. Members of multi-angulated beams adopt the box beam with Q345B steel, with dimensions of cross section $300 \mathrm{~mm} \times 200 \mathrm{~mm} \times 10 \mathrm{~mm}$ (height $\times$ width $\times$ wall thickness). Additionally, the cross section area of the cable, which is simulated by tension-only bar element LINK10, is $78.5 \mathrm{~mm}^{2}$. The cross-section area of struts, which is simulated by LINK8, is $706.5 \mathrm{~mm}^{2}$. The Young's modulus of steel beams, struts and cables are 210 MPa, $210 \mathrm{MPa}$ and $180 \mathrm{MPa}$, respectively.

\subsection{Distribution of Initial Prestress Level of Lower Cable-strut System}

In order to resist external loads and prevent the loose of cables, enough vertical forces must be provided by the initial prestress in cables. As stated by Kitipornchai et al. [8], the suspen-dome system is very rigid, and the nonlinear deformation is very small even under a large external load. As a result, the method of superposition can be applied in the analysis of the distribution of initial prestress level without introducing a large degree of error. Then the suspen-dome structure is divided into two parts: the top single-layer dome and the lower cable-strut system. We add the restrictions to the lower cable-strut system for the force finding analysis.

The number of independent inextensional mechanisms is five and the number of independent states of self-stress is also five. The lower cable-strut system have five independent rings after adding the restrictions, so the independent state of self-stress should be the stress distribution of every ring respectively. Because of the symmetry of the structure, there are three types of elements in every state of self-stress: radial cables, hoop cables and vertical struts. From the equilibrium of every nodes of the lower cable-strut system as shown in Figure 6, we can obtain the relationship between the forces of hoop cables, vertical struts and radial cables. It can be seen from Figure 6 that the relation between the hoop cable forces $N_{\mathrm{h}}$ and radial cable forces $N_{\mathrm{r}}$ is

$$
N_{r} \sin \gamma \cos \frac{\beta}{2}=N_{h} \cos \frac{\alpha}{2}
$$


where $\alpha$ denotes the angle between adjacent hoop cables, $\beta$ denotes the horizontal projection of the angle between adjacent radial cables, $\gamma$ denotes the angle between the radial cable and the vertical axis. Moreover, the forces relation between the vertical struts $N_{\mathrm{v}}$ and radial cables $N_{\mathrm{r}}$ can be given as

$N_{v}=2 N_{r} \cos \gamma$

Therefore, the state of self-stress of every ring of lower cable-strut system can be obtained from Eqs. 1 and 2.

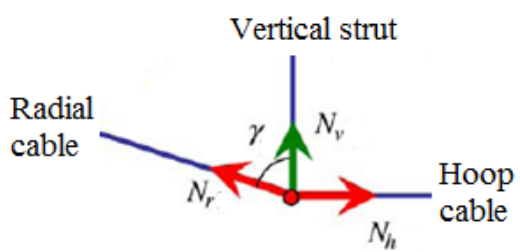

(a) Vertical projection

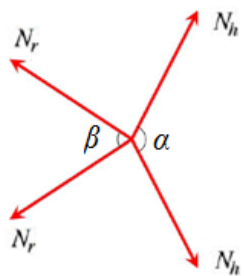

(b) Horizontal projection

Figure 6. Equilibrium of a Node of Lower Cable-strut System

The lower structure is divided into five independent sub-structures, thus the force distribution is not affected by other rings. The combination factor of five independent states of self-stress must be determined by other condition. The optimization theory is used in this paper to decide the combination factor.

Step 1 The nodal displacement of all nodes of single-layer dome under dead load can be assembled in the vector $\boldsymbol{d}_{\boldsymbol{s}}$.

Step 2 The nodal displacement of all nodes of single-layer dome related to the state of self-stress of lower cable-strut system can be assembled in the vector $\boldsymbol{d}_{\boldsymbol{i}}(\mathrm{i}=1, \ldots, \mathrm{s})$.

Step 3 Supposed the combination factor of every independent state of self-stress is $\alpha_{i}(\mathrm{i}=1, \ldots, \mathrm{s})$. Then, the nodal displacements of all nodes of single-layer dome is $\boldsymbol{d}$, can be written

$d=\sum_{i=1}^{s} \alpha_{i} d_{i}+d_{s l}=\left[\begin{array}{llll}d_{1} & d_{2} & \cdots & d_{s}\end{array}\right]\left[\begin{array}{c}\alpha_{1} \\ \alpha_{2} \\ \vdots \\ \alpha_{s}\end{array}\right\}+d_{s l}$

The objective function is

$\min . \quad \psi\left(\alpha_{i}\right)=\|d\|, i=1 \sim \mathrm{s}$

Then we can obtian the initial prestress in hoop cables from the outer ring to the inner ring are 100MPa, 68.08 MP, 38.47 MPa, 15.67 MP, 3.25 MPa, respectively.

\subsection{Stability Behavior}

The influence of the material nonlinearity on the statbility of single-layer lattice shell or gird shell structures is significant [23]. Moreover, the model containing only geometry nonlinearity will over estimate the failure load of the structure. As to the radially retractable suspen-dome, a new type structure form, the influence of material nonlinearity is still unclear. Therefore, the model considering geometry nonlinear only (Model 1) and the model considering both geometry and material nonlinearity (Model 2) are investigated. 
Moreover, the stability behaviors of the radially retractable suspen-dome and the corresponding single-layer grid shell are studied to investigate the effects of lower cable-strut system. The load displacement curves for the node with the maximum vertical displacement are given in Figs. 7 and 8. The load factor is defined as the ratio between the applied load and the design load. Under the symmetric load case (load 1) and the anti-symmetric load case (load 2), the failure load of the radially retractable suspen-dome considering only geometry nonlinearity is larger than that the system considering both geometry and material nonlinearity, i.e. 9.49\% higher in load 1 and $14.63 \%$ higher in load 2 . Therefore, the model considering geometry nonlinearity only leads to a relatively unsafe result and both geometry and material nonlinearity need to be considered in the analysis of the structure.

In addition, it can be found that under both load cases, the first half parts of load displacement curves of the two models are overlapped. It indicates that the influence of the material nonlinearity at the beginning of the loading process is slight. With the increase of the loading, the structure shows plastic behavior. Then the slope of the load displacement curve decreases remarkably and the ultimate capacity drops greatly for the elasto-plastic buckling analysis. For the elasto-plastic failure loads of the two modes, the suspen-dome increases by $146.91 \%$ and $10.05 \%$ than the corresponding grid shell under the load 1 and the load 2, respectively.

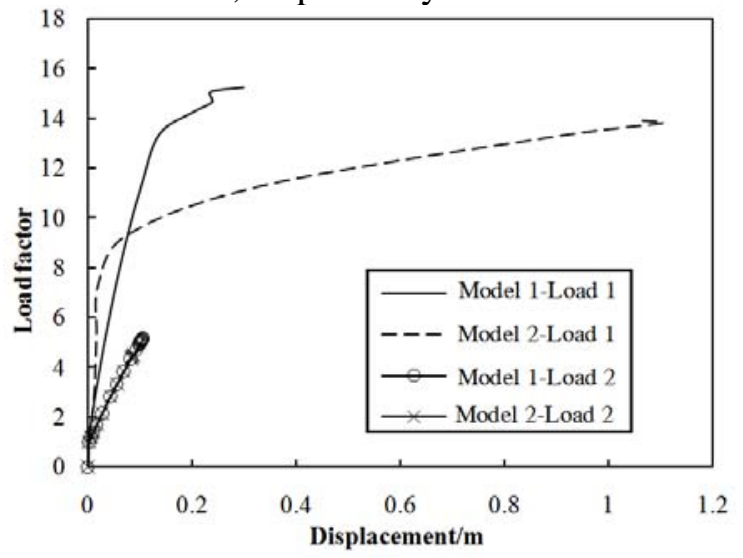

Figure 7. Load Displacement Curve of the Retractable Suspen-dome

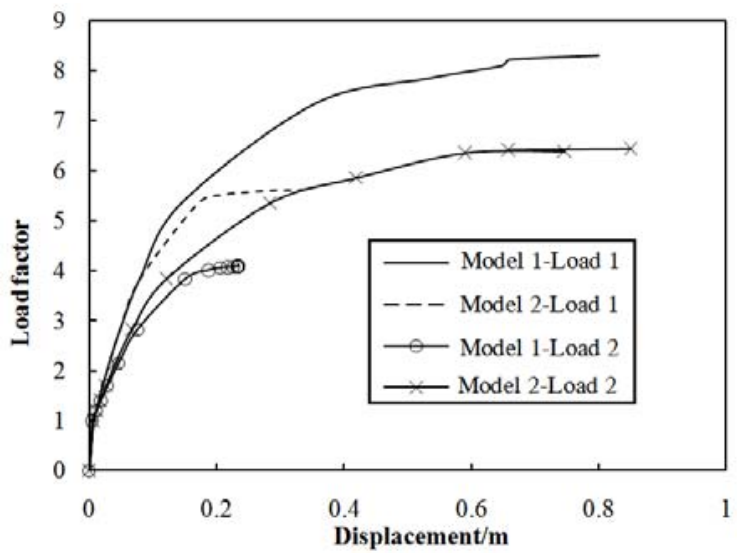

Figure 8. Load Displacement Curve of the Corresponding Single-layer Grid Shell 


\section{PARAMETRIC STUDIES}

In order to better understand the influence of each parameter of the radially retractable suspen-dome on the elasto-plastic ultimate capacity of the structure, effects of the rise-span ratios, steel beams sections, initial cable prestress, cable areas are investigated in this paper.

\subsection{Influence of Rise-span Ratios}

The elasto-plastic analyses as for the example structure were carried out with different rises (keeping the span constant) to study the effect of rise-span ratios. The rise-to-span ratios correspond to $0.1,0.15,0.2$ and 0.25 , respectively. The load displacement curves of the suspen-dome with different rise-span ratios and the corresponding failure load factors are shown in Figure 9. It can be found that the rise-span ratio has a great influence on the stability behavior of the hybrid grid shell and the failure load increases with the increase of the rise-span ratio. It can be concluded that the rise -span ratio is a key factor of the stability capability of the hybrid grid shell.

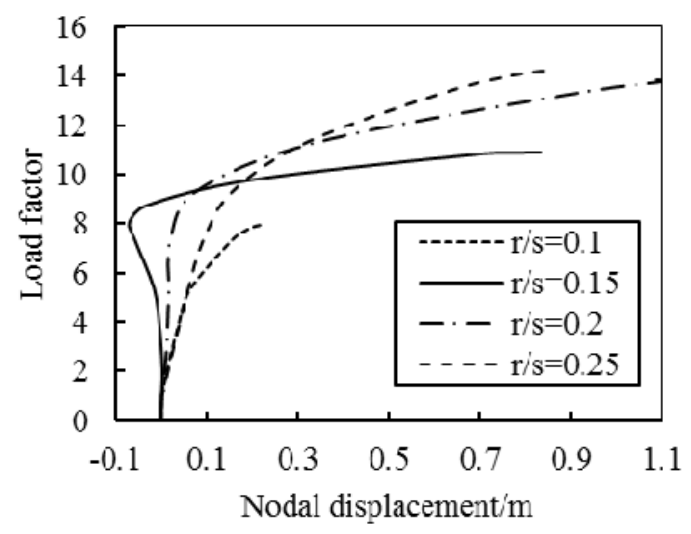

(a) Load displacement curves for Load 1

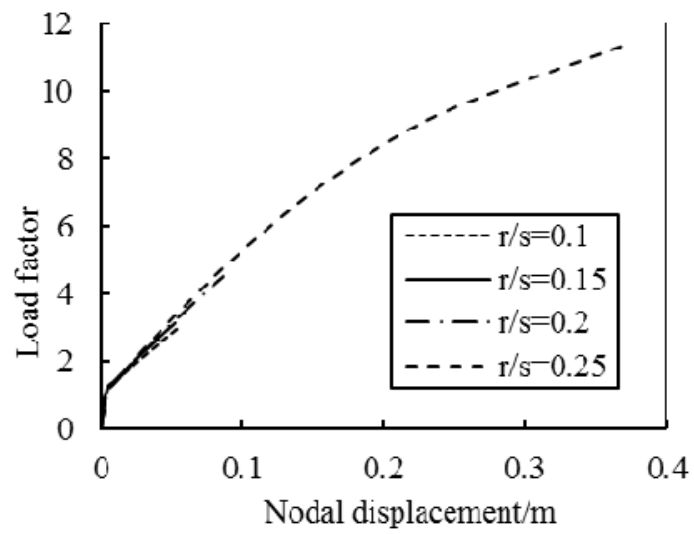

(b) Load displacement curves for Load 2

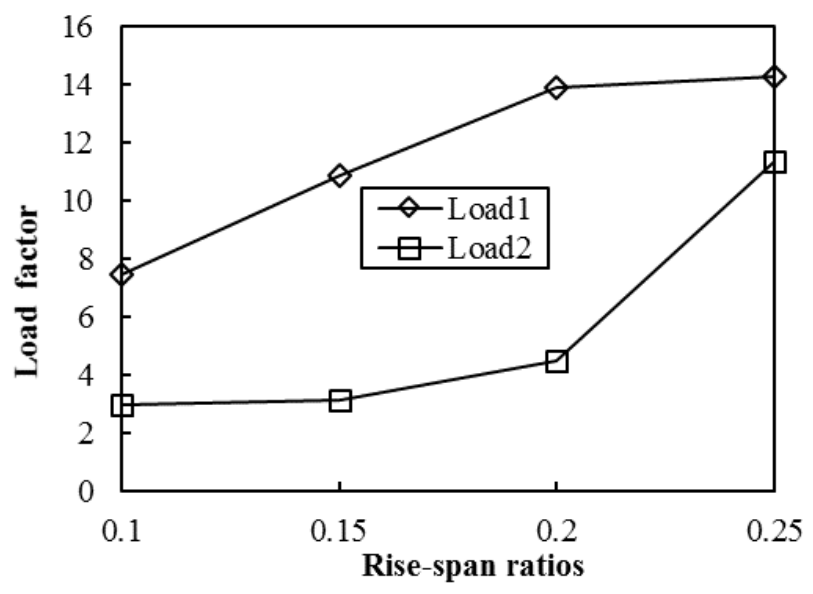

(c) Failure load factor

Figure 9. Influence of Rise-span Ratio 


\subsection{Influence of the Steel Beam Section}

When the geometry of the structure is identified, the cross-section of steel beams can be an important factor that affects the buckling capacity of the suspen-dome. This is because the stiffness of the single-layer grid shell mostly relies on the stiffness of beams, which mainly includes the beam axial stiffness EA and flexural stiffness EI. Regarding the beam rigidity of the basic model as $\mathrm{E}_{0} \mathrm{~A}_{0}$ and $\mathrm{E}_{0} \mathrm{I}_{0}$, the stability behavior of the structure is investigated by changing the beam stiffness coefficients EA/ E0 $\mathrm{A}_{0}$ and $\mathrm{EI} / \mathrm{E}_{0} \mathrm{I}_{0}$.

Five different steel beams sections, $250 \mathrm{~mm} \times 150 \mathrm{~mm} \times 10 \mathrm{~mm}, 300 \mathrm{~mm} \times 200 \mathrm{~mm} \times 10 \mathrm{~mm}$, $350 \mathrm{~mm} \times 200 \mathrm{~mm} \times 10 \mathrm{~mm}, 400 \mathrm{~mm} \times 200 \mathrm{~mm} \times 10 \mathrm{~mm}, 450 \mathrm{~mm} \times 200 \mathrm{~mm} \times 10 \mathrm{~mm}$, are chosen to study the influence of beam sections. The load displacement curves are given in Figure 10. It shows that the tendency of load displacement curves is consistent for different beam sections. It can also be found that the failure load factor of the suspen-dome improves with the rise of the bar stiffness. For the symmetric load case, the failure load drops $47.25 \%$ when the axial stiffness of bars decreases by $20 \%$ and it increases by $14.75 \%$ when the flexural stiffness is raised by $30 \%$. For the anti-symmetric load case, the failure load drops $51.67 \%$ when the axial stiffness decreases by $20 \%$ and it increases by $258.84 \%$ when the flexural stiffness is raised by $30 \%$. Meanwhile, the load displacement curves can reveal the characteristic of the structural stiffness. It can be obtained from Figure 10 that the increase of beam sections will enhance the structural stiffness of the hybrid grid shell.

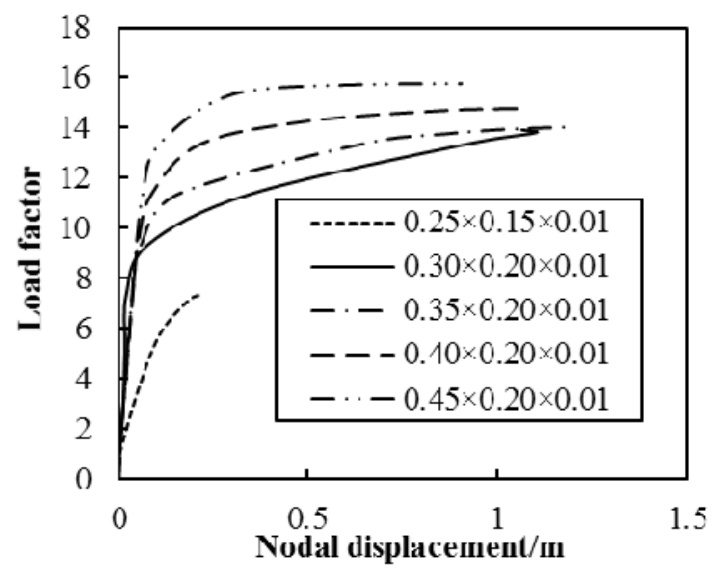

(a) Load displacement curve under Load 1

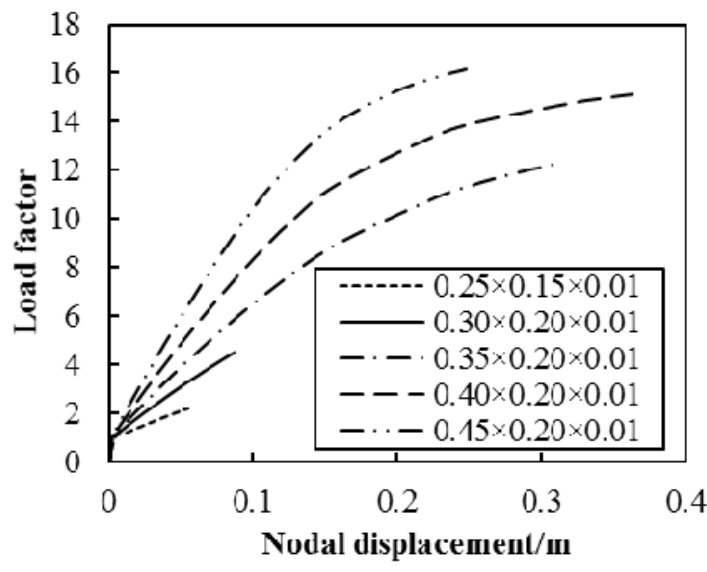

(b) Load displacement curve under Load 2

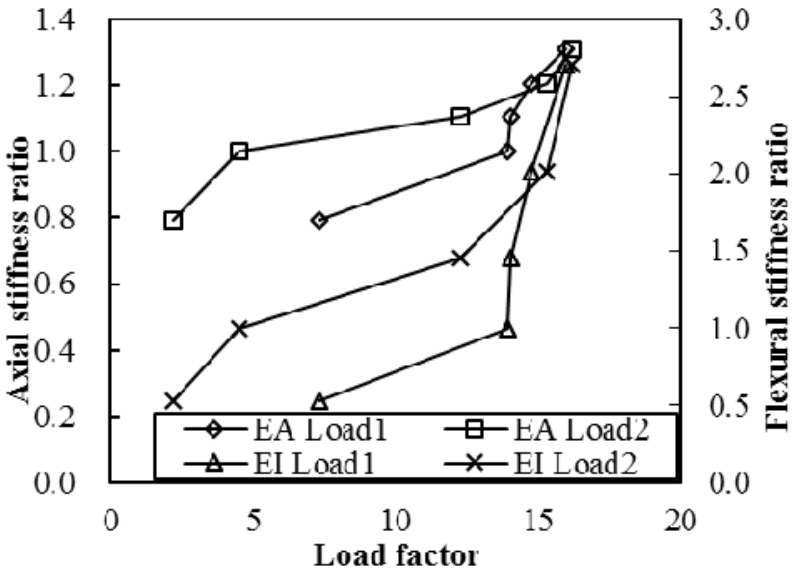

(c) Failure load factor

Figure 10. Influence of the Steel Beam Sections 


\subsection{Influence of Hoop and Radial Cable Areas}

The area of hoop and radial cables may also be important factors that affect the elasto-plastic buckling behavior of the retractable hybrid grid shell. The load displacement curves and the failure load against the area of hoop cables are shown in Figure 11. The diameters of hoop cables correspond to $8 \mathrm{~mm}, 10 \mathrm{~mm}, 12 \mathrm{~mm}, 15 \mathrm{~mm}$ and $20 \mathrm{~mm}$ in Figure 11, respectively. In Figure 11(c), the horizontal coordinate is the cable area ratio, $m$, which is defined as the ratio of cable areas to the cable area of the basic model. It can be found from Figure 11 that, for both load cases, the failure load factor rises first and then decrease with the increase of the hoop cable area. The load displacement curves also show that the effect of the cable area on the structural stiffness is positive first and then negative. However, it can also be found that the hoop cable area has a limited influence on the ultimate capacity of the suspen-dome. Hence, it is not economical to increase the hoop cable area to improve the structure stability behavior.

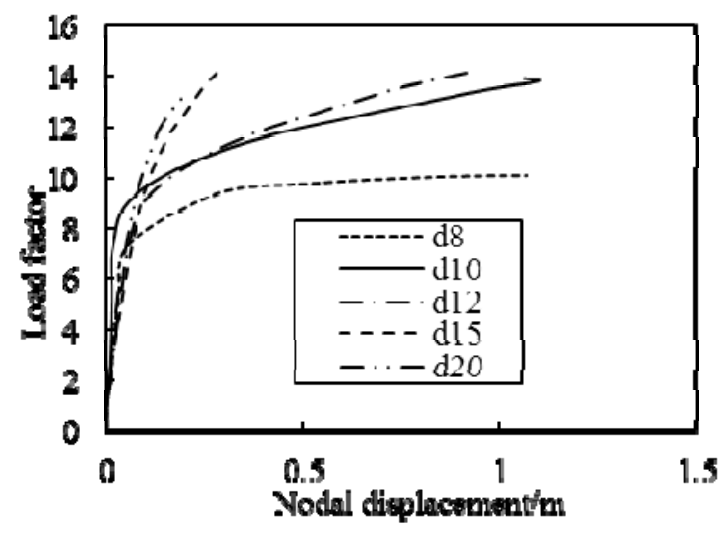

(a) Load displacement curve under Load 1

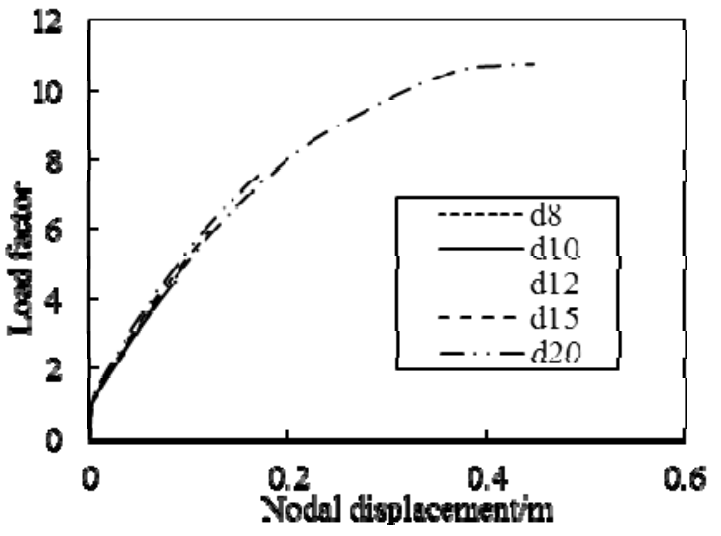

(b) Load displacement curve under Load 2

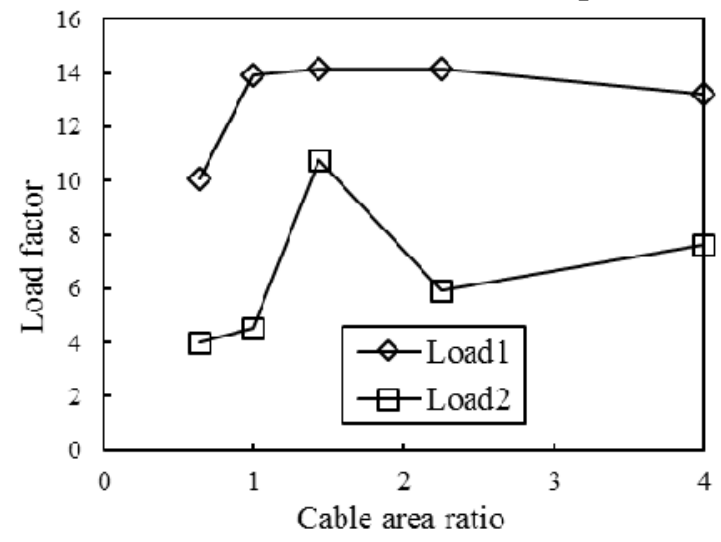

(c) Failure load factor

Figure 11. Influence of the Hoop Cable Section

The load displacement curves and the failure load against the area of radial cables are shown in Figure 12. The diameters of radial cables correspond to $8 \mathrm{~mm}, 10 \mathrm{~mm}, 12 \mathrm{~mm}, 15 \mathrm{~mm}$ and $20 \mathrm{~mm}$ in Figure 12, respectively. It can be found from Figure 12 that, for the symmetric load case, the failure load factor rises with the increase of the radial cable area. However, for the asymmetric load case, the failure load decrease with the increase of the radial cable area. Moreover, it can also be found that the radial cable area has a limited influence on the ultimate capacity of the suspen-dome. 


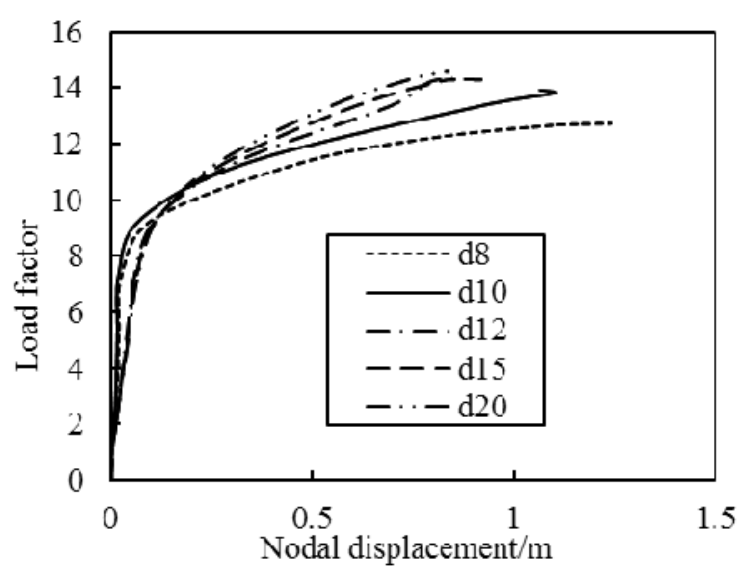

(a) Load displacement curve under Load 1

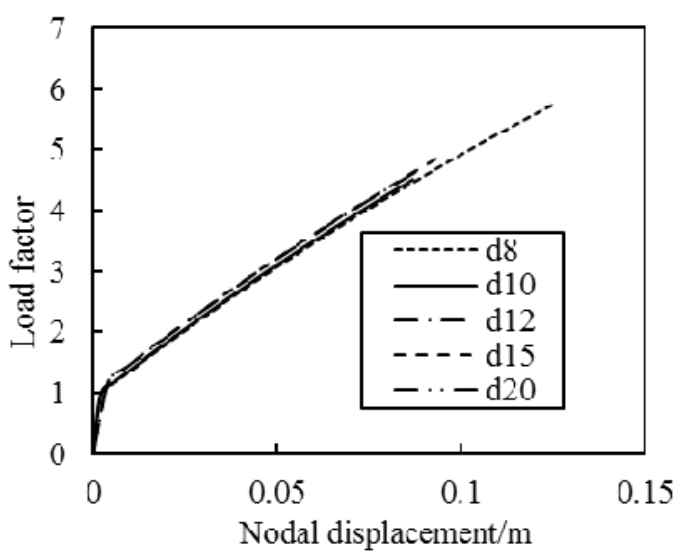

(b) Load displacement curve under Load 2

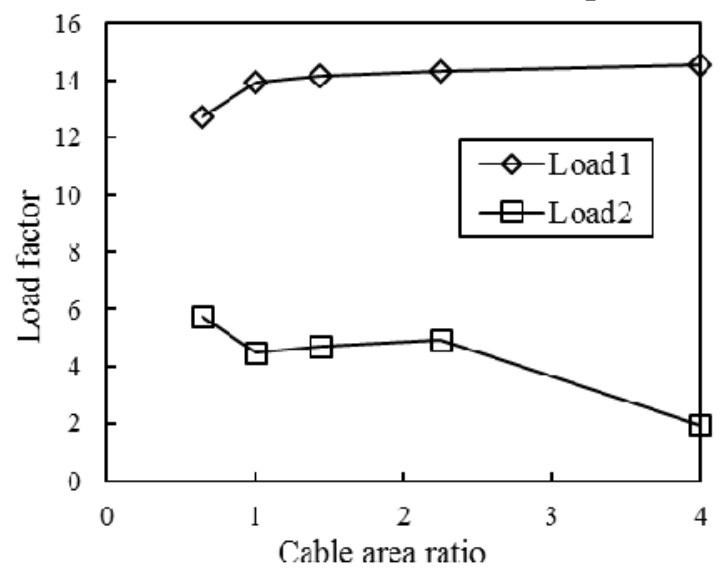

(c) Failure load factor

Figure 12. Influence of the Radial Cable Section

\subsection{Influence of Cable-strut Prestress Levels}

To study the effect of cable-strut pre-stress levels, the initial stresses of hoop cables in the outer ring are set to $0 \mathrm{MPa}, 50 \mathrm{MPa}, 100 \mathrm{MPa}, 150 \mathrm{MPa}$ and $200 \mathrm{MPa}$, respectively. The initial stresses of other cables and struts can be obtained with the method given in Section 3.2. The results under both load cases are shown in Figure 13. It can be seen from Figure 13 that the ultimate capacity of the suspen-dome enhances with the increase of the initial pre-stress level, but the rate of the increase is slight. The ultimate load just increases $0.29 \%$ when the prestress level doubles, and it just decreases by $0.36 \%$ when the prestress level is reduced to the half. It can be concluded that the cable-strut pre-stress contributes little to the ultimate capacity of the structure. Therefore, it is not a wise choice to improve the ultimate capacity of the structure by increasing the initial prestress in lower cable-strut system only. 

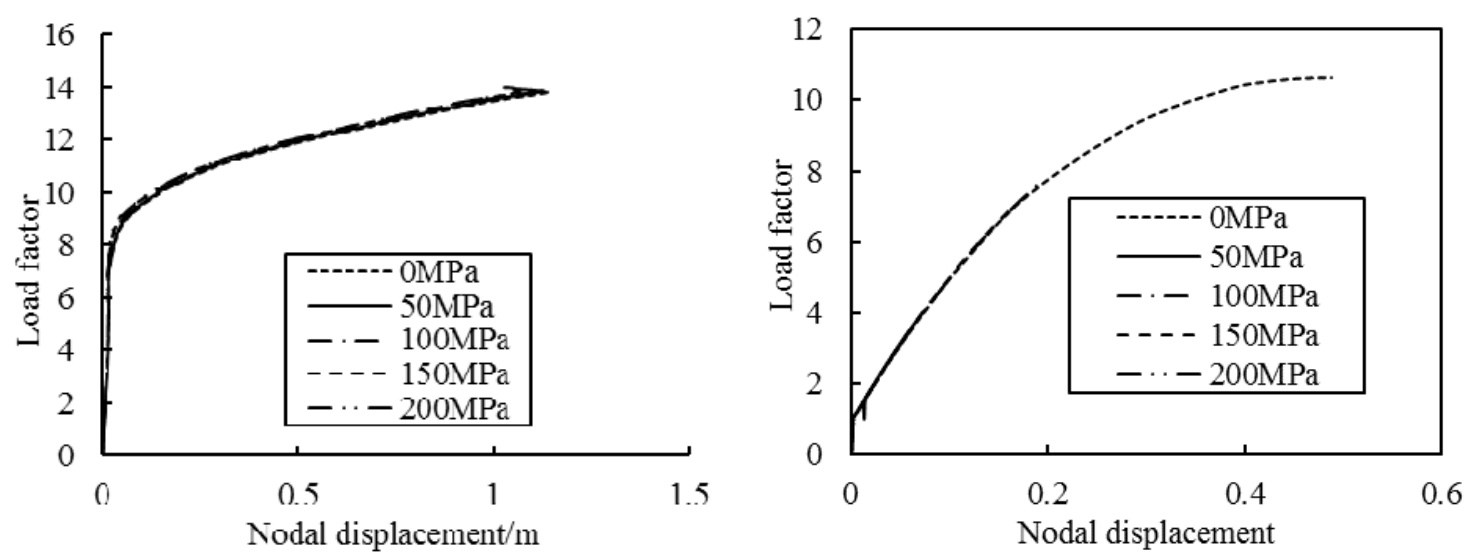

$\begin{array}{lll}\text { (a) Load displacement curve under Load } 1 & \text { (b) Load displacement curve under Load } 2\end{array}$

Figure 13. Influence of Cable-strut Prestress Levels

\subsection{Influence of Strut Sections}

Different strut sections with diameters of $20 \mathrm{~mm}, 25 \mathrm{~mm}, 30 \mathrm{~mm}, 35 \mathrm{~mm}$ and $40 \mathrm{~mm}$ are adopted to conduct the stability analysis of the structure. Figure 14 shows the influence of the strut section on the elastoplastic ultimate capacity of the suspen-dome. It can be seen from this figure that the load displacement curves are nearly overlapped, which indicates none influence of the strut section on the elastoplastic ultimate capacity. Thus, when choosing the strut section, only its own stability needs to be considered.

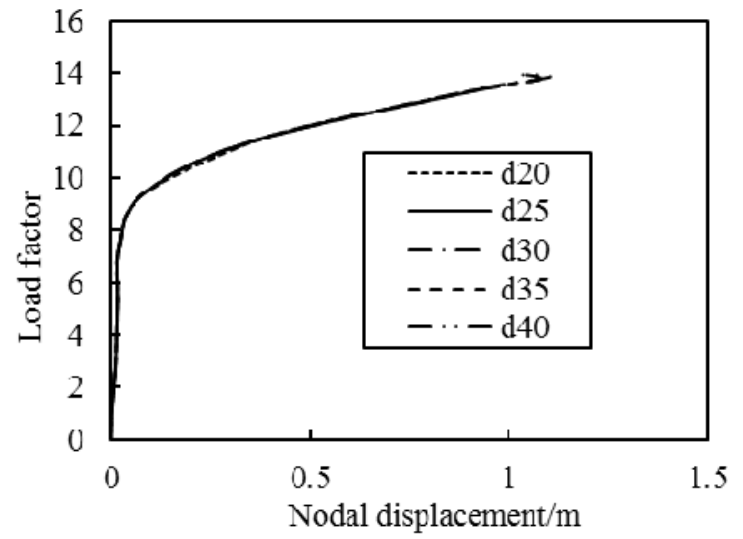

(a) Load displacement curve under Load 1

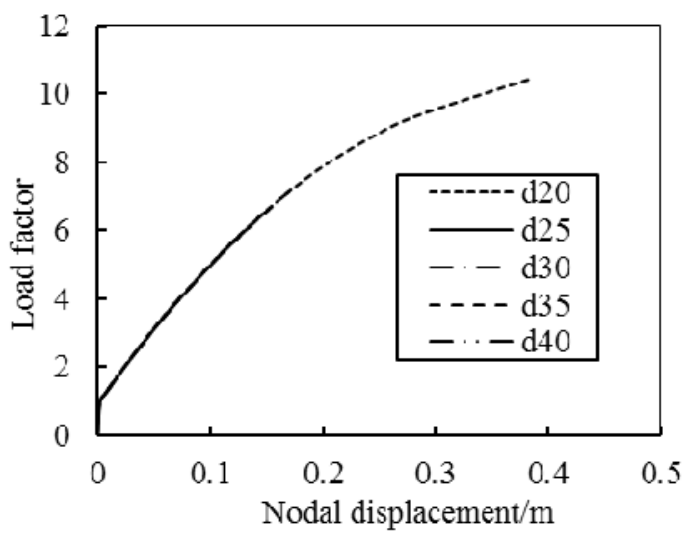

(b) Load displacement curve under Load 2

Figure 14. Influence of Strut Sections

\section{EFFECTS OF IMPERFECTIONS ON THE STABILITY BEHAVIOR}

For the long-span spatial structures, the inaccuracy in construction and installation may trigger a great influence on the forces of the structure. The single-layer grid shell structure is sensitive to imperfections $[24,25]$. As a new type of single-layer grid shell, the effect of imperfections on the stability of the radially retractable hybrid grid shell has not been studied. According to the European standard [26] and Chinese code [27], the geometrical imperfection should be taken into account in the non-linear analysis in order to model the structure in a realistic way.

Several methods are available to analyze geometrical imperfections, i.e. the random imperfection mode method [28], the consistent imperfection mode method. In the later method, the imperfection distribution is assumed to be consistent with the deflected shapes, such as eigenvalue buckling 
modes and nonlinear buckling shapes. The consistent imperfection mode method is used in this paper. The steps of the imperfect buckling analysis can be concluded as following:

(1) Conducting the eigenvalue buckling analysis or nonlinear buckling analysis of the structure to obtain its buckling modes;

(2) Nomalizing the buckling modes deriving from the eigenvalue buckling analysis or nonlinear buckling analysis;

(3) Modifying the joint coordinates of the finite model according to the previous step;

(4) Conducting the static elastoplastic analysis of the imperfect structure to obtain its ultimate capacity.

As suggested in Cai et al. [24, 25], we have set up the following shapes of imperfections for hybrid grid shell: (1) the first four eigenvalue buckling modes; (2) the displacement shape of the loaded structure obtained from a geometrical non-linear elastic buckling analysis. Both imperfections are easy to compute and therefore can be often used by engineers. The first four eigenvalue buckling modes and the nonlinear buckling mode of the hybrid grid shell under both load cases are given in Figure 15.

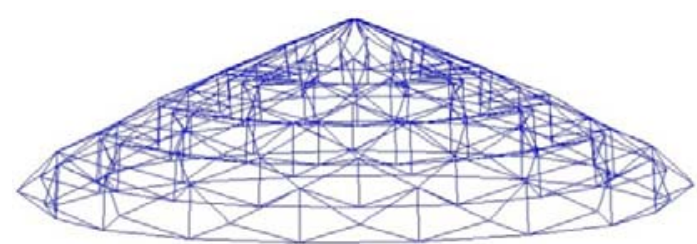

First eigenvalue buckling mode (Load1)

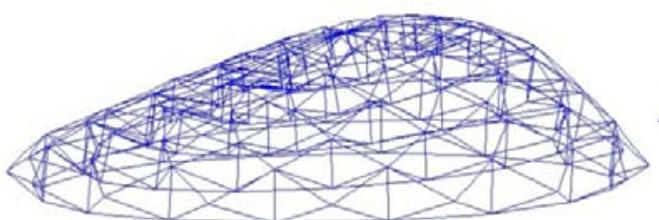

Second eigenvalue buckling mode (Load1)

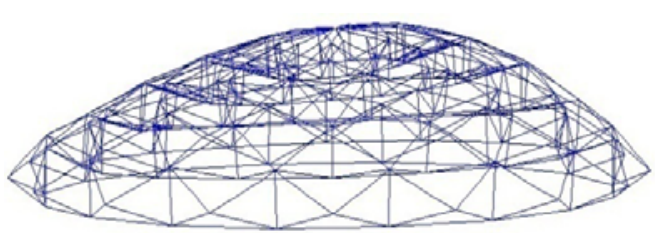

Third eigenvalue buckling mode (Load1)

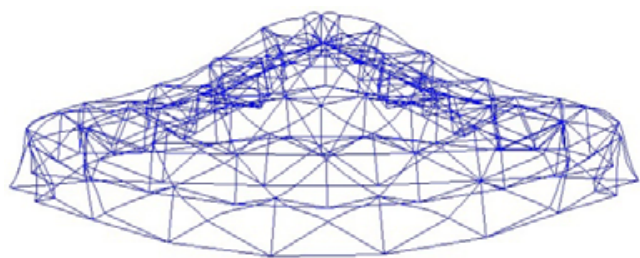

Fourth eigenvalue buckling mode (Load1)

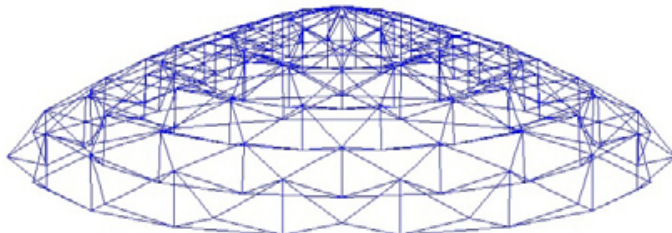

Nonlinear buckling mode (Load1)

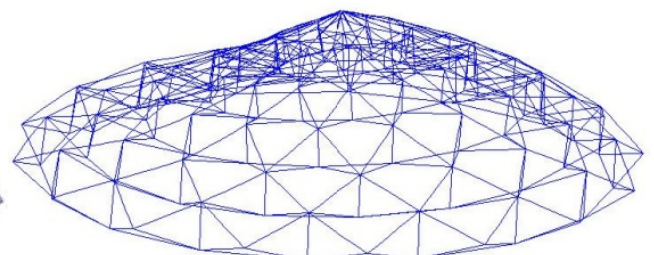

First eigenvalue buckling mode (Load2)

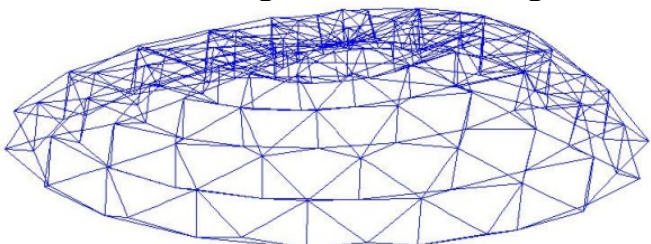

Second eigenvalue buckling mode

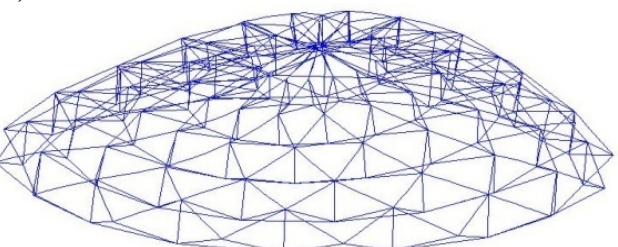

Third eigenvalue buckling mode (Load2)

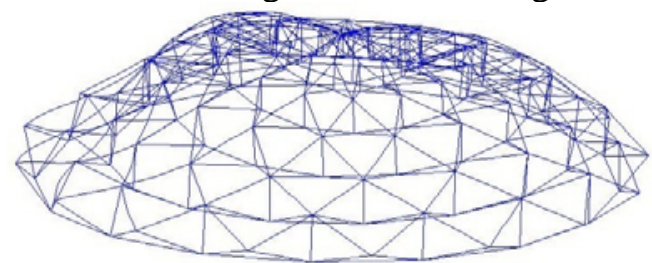

Fourth eigenvalue buckling mode

(Load2)

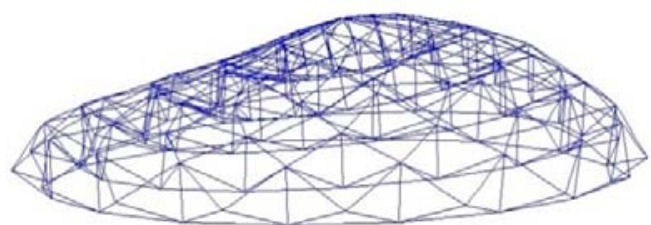

Nonlinear buckling mode (Load2) 
Figure 15. Buckling Modes of the Radially Retractable Suspen-dome

Figure 16 show the failure load factors for different suspen-dome, including the perfect structure. The maximum imperfections of all shapes have been scaled to span/300. It is clear from the figure that the failure load of the hybrid structure under both load cases is significantly affect by the geometric imperfections. It can be found that the lowest buckling load is predicted with the nonlinear buckling mode. Therefore, this imperfection shape is thus employed in all the following analyses.

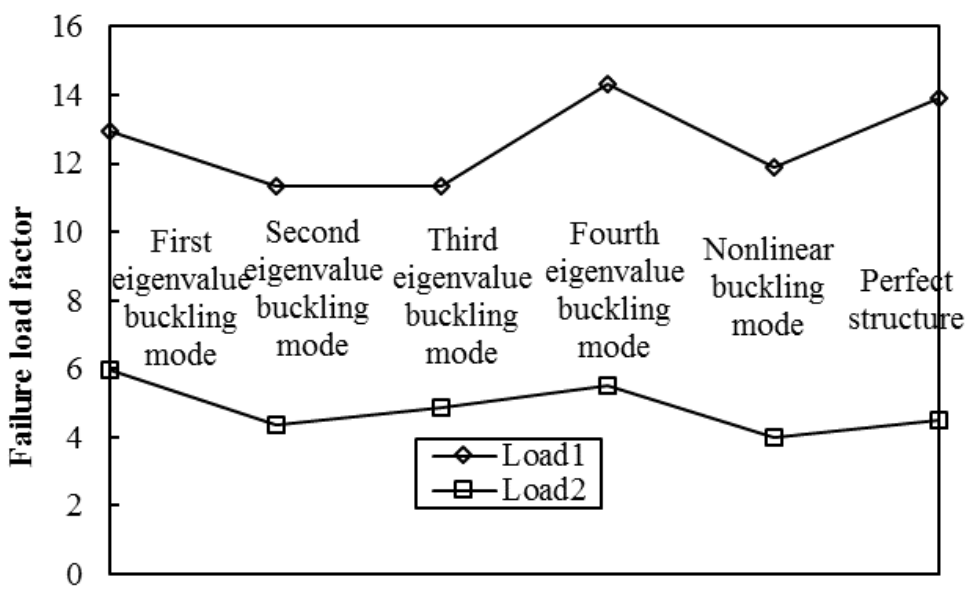

Figure 16. Influence of Imperfection Modes on the Failure Load of Suspen-domes

\section{CONCLUSIONS}

The buckling capacity of the radially suspen-dome was investigated in this paper. The geometrical non-linear elastic buckling analyses was carried our first. By taking into consideration of material non-linearity using elasto-plastic analyses, the behavior of hybrid structures was found significantly different. The results show that the buckling capacity is reduced by taking account of material non-linearity. Then the effects of different geometrical and parameters on the failure loads were studied. The analysis results show that under a particular span, the buckling capacity increases with the increase of the rise-span ratio. Moreover, increasing the cross-section of steel beams notably improves the stability performance of the structure. However, the section area and pre-stress of lower cable-strut system pose virtually little effect on the structural stability. Finally, the effects of imperfections on the stability behavior were also investigated. It can be found that radially retractable suspen-dome is highly imperfection sensitive and the reduction of the failure load due to imperfections can be considerable. Furthermore, when imposing imperfections, the proper shape is also important. The results show that the nonlinear buckling mode is the most critical imperfection shape. 


\section{ACKNOWLEDGEMENTS}

The work presented in this article was supported by the National Natural Science Foundation of China (Grant No. 51308106 and No. 51578133), a Project Funded by the Priority Academic Program Development of Jiangsu Higher Education Institutions, and the Excellent Young Teachers Program of Southeast University.

\section{REFERENCES}

[1] Mao, Decan and Luo, Yaozhi, "Analysis and Design of a Type of Retractable Roof Structure”, Advances in Structural Engineering, Vol. 11, No. 4, pp. 343-354.

[2] Van, Mele T, De, Temmerman N, De, Laet L. and Mollaert, M., "Scissor-hinged Retractable Membrane Structures”, Int. J. Structural Engineering, 2010, Vol. 1, No. 3/4, pp. 374-396.

[3] De, Temmerman N., Alegria, Mira L. and Vergauwen, A., "Feasibility of the Universal Scissor Component (USC): Building a Full-scale Deployable Dome”, Journal of the International Association for Shell and Spatial Structures, 2012, Vol. 53, No. 4, pp. 227 236.

[4] Hoberman, C., "Reversibly Expandable Doubly-curved Truss Structures”, US Patent 4, 942,700, 1990.

[5] Hoberman, C., Radial Expansion Retraction Truss Structure”, US Patent Vol. 5,024,031, 1991.

[6] Hoberman, C., “Art and Science of Folding Structures”, Sites, Vol. 24: pp. 61-69, 1992.

[7] Cai, J.G., Xu, Y.X. and Feng, J., "Kinematic Analysis of Hoberman's Linkages with the Screw Theory”, Mechanism and Machine Theory, 2013, Vol. 63, pp. 28-34.

[8] You, Z. and Pellegrino, S., "Foldable Bar Structures", International Journal of Solids and Structures, 1997, Vol. 34, No. 15, pp. 1825-1847.

[9] Teall, M.J., Deployable Roof Structures. Masters Dissertation, University of Cambridge, UK, 1996.

[10] Cai, J.G., Jiang, C., Deng, X.W., etc., "Static Analysis of a Radially Retractable Hybrid Grid Shell in the Closed Position”, Steel and Composite Structures, 2015, Vol. 18, No. 6, pp. 1391-1404.

[11] Abedi, K. and Parke, G.A.R., "Progressive Collapse of Single-layer Braced Domes", International Journal of Space Structures, 1996, Vol. 11, No. 3, pp. 291-306.

[12] Kawaguchi, M., Abe, M. and Tatemichi, I., "Design, Tests and Realization of Suspend-dome System”, Journal of International Association of Shell and Spatial Structures, 1999, Vol. 40, No. 131, pp. 179-192.

[13] Kawaguchi, M., Abe, M., Hatato, T., et al., "Structural Tests on the "Suspen-dome” System", In: Proceedings of the IASS symposium. Atlanta, USA, 1994.

[14] Kang, W.J., Chen, Z.H., Lam, H., et al., "Analysis and Design of the General and Outmost-ring Stiffened Suspen-dome Structures”, Engineering Structures, 2003, Vol. 25, No. 13, pp. 1685-1695.

[15] Kitipornchai, S., Kang, W.J., Lam, H., et al., "Factors Affecting the Design and Construction of Lamella Suspend-dome Systems”, Journal of Construction Steel Research, 2005, Vol. 61, No. 6, pp. 764-785.

[16] Li, K.N. and Huang, D.H., "Static Behavior of Kiewitt6 Suspendome”, Structural Engineering and Mechanics, 2011, Vol. 37, No. 3, pp. 309-320.

[17] Liu, H.B., Chen, Z.H. and Zhou, T., "Research on the Process of Pre-Stressing Construction of Suspen-Dome Considering Temperature Effect”, Advances in Structural Engineering, 2012, Vol. 15, No. 3, pp. 489-493. 
[18] Li, Z.Q., Zhang, Z.H., Dong, S.L., et al., "Construction Sequence Simulation of a Practical Suspen-dome in Jinan Olympic Center”, Advanced Steel Construction, 2012, Vol. 8, No. 1, pp. 38-53.

[19] Chen, Z.H., Wu, Y.J., Yin, Y., et al., "Formulation and Application of Mmulti-node Sliding Cable Element for the Analysis of Suspen-Dome Structures”, Finite Elements in Analysis and Design, 2010, Vol. 46, No. 9, pp. 743-750

[20] Liu, H.B., Han, Q.H., Chen, Z.H., et al. "Precision Control Method for Prestressing Construction of Suspen-dome Structures”, Advanced Steel Construction, 2014, Vol. 10, No. 4, pp. 404-425

[21] Guo J.M., Yuan X.F., Li Y.Y., et al., "A Simple Approach for Force Finding Analysis of Suspended-Domes Based on the Superposition Principle”, Advances in Structural Engineering, 2014, Vol. 17, No. 11, pp. 1681-1691.

[22] Zhou, Z., Feng, Y.L., Meng, S.P., et al., “A Novel form Analysis Method Considering Pretension Process for Suspen-dome Structures”, KSCE Journal of Civil Engineering, 2014, Vol. 18, No. 5, pp. 1411-1420.

[23] Fan, F., Cao, Z.G. and Shen, S.Z., "Elasto-plastic Stability of Single-layer Reticulated Shells”, Thin-Walled Structures, 2010, Vol. 48, No. 10-11, pp. 827-836.

[24] Cai, J.G., Gu, L.M., Xu, Y.X., Feng, J. and Zhang, J., "Nonlinear Stability of a Single-layer Hybrid Grid Shell”, Journal of Civil Engineering and Management, 2012, Vol. 18, No. 5, pp. 752-760.

[25] Cai, J.G., Zhou, Y., Xu, Y.X. and Feng, J., “Non-linear Stability Analysis of a Hybrid Barrel Vault Roof, Steel and Composite Structures, 2013, Vol. 14, No. 6, pp. 571-586.

[26] Eurocode 2003, European Standard. 3: Design of Steel Structures, Parts 1-6: Strength and Stability of Shell Structures, European Committee for Standardisation, 2004.

[27] JGJ7-2010, Technical Specification for Space Frame Structures, Beijing: China Architecture Industry Press [in Chinese], 2010.

[28] Yamada, S., Takeuchi, A., Tada, Y. and Tsutsumi, K., "Imperfection-sensitive Overall Buckling of Single-layer Lattice Domes”, J. Eng Mech, 2001, Vol. 4, pp. 382-396. 